\title{
Barriers to recovery and recommendations for change: the Pennsylvania Consensus Conference on psychiatry's role.
}

\author{
Joseph A. Rogers \\ Mental Health Association of Southeastern Pennsylvania \\ Michael J. Vergare \\ Thomas Jefferson University \\ Richard C. Baron \\ University of Pennsylvania \\ Mark S. Salzer \\ University of Pennsylvania \\ Follow this and additional works at: https://jdc.jefferson.edu/phbfp \\ Part of the Psychiatry Commons \\ Let us know how access to this document benefits you
}

\section{Recommended Citation}

Rogers, Joseph A.; Vergare, Michael J.; Baron, Richard C.; and Salzer, Mark S., "Barriers to recovery and recommendations for change: the Pennsylvania Consensus Conference on psychiatry's role." (2007). Department of Psychiatry and Human Behavior Faculty Papers. Paper 38.

https://jdc.jefferson.edu/phbfp/38

This Article is brought to you for free and open access by the Jefferson Digital Commons. The Jefferson Digital Commons is a service of Thomas Jefferson University's Center for Teaching and Learning (CTL). The Commons is a showcase for Jefferson books and journals, peer-reviewed scholarly publications, unique historical collections from the University archives, and teaching tools. The Jefferson Digital Commons allows researchers and interested readers anywhere in the world to learn about and keep up to date with Jefferson scholarship. This article has been accepted for inclusion in Department of Psychiatry and Human Behavior Faculty Papers by an authorized administrator of the Jefferson Digital Commons. For more information, please contact: JeffersonDigitalCommons@jefferson.edu. 


\section{Barriers to Recovery and Recommendations for Change: The Pennsylvania Consensus Conference on Psychiatry's Role}

Joseph A. Rogers, A.A. Michael J. Vergare, M.D. Richard C. Baron, M.A. Mark S. Salzer, Ph.D.

Objective: Recovery has emerged over the past decade as a dominant theme in public mental health care. Methods: The 2006 Pennsylvania Consensus Conference brought together 24 community psychiatrists to explore the barriers they experienced in promoting recovery and their recommendations for change. Results: Twelve barriers were identified and classified into one of three categories: psychiatry knowledge, roles, and training; the need to transform public mental health systems and services; and environmental barriers to opportunity. Participants made 22 recommendations to address these barriers through changes in policies, programs, and psychiatric knowledge and practice. Conclusions: The recommendations identify areas for change that can be accomplished through individual psychiatrist action and organized group efforts. (Psychiatric Services 58:1119-1123, 2007)

Recovery has emerged as the dominant theme in the transformation of public mental health policy, practice, and research (1-5) and is at the heart of the report from the President's New Freedom Commission on Mental Health, Achieving the Promise: Transforming Mental Health Care in America (6). The expansion of recovery's influence, however, has proceeded without an exploration of how community psychiatry and its practitioners view recovery and its challenges $(7,8)$. Specifically, what do psychiatrists think about recovery, their own role in promoting hope, empowerment, and opportunity, and the barriers they may face in moving the recovery agendal forward? What recommendations do they have for overcoming those barriers and enhancing their ability to promote recovery?

\section{Methods}

This brief report presents findings from a one-day meeting in Philadelphia in January 2006 of 24 psychiatrists from institutional and community settings who were clinicians, administrators, and educators. After a series of plenary presentations that reviewed the fundamentals of recovery, participants chose to attend one of three work groups that focused on policy, program, or practice issues. Each group was asked to address two questions: What do you perceive as barriers to expanding psychiatry's role in supporting recovery? and What recommendations would you make to address these barriers at that level and strengthen psychiatry's efforts in promoting recovery? The facilitator of each group documented the points that were raised. A final large group session was held to discuss the identified barriers and recommendations. Participants were informed that the issues and recommendations they raised would be captured in a report, presented here. The project was determined to be exempt from institutional review board approval by the Office of Regulatory Affairs at the University of Pennsylvania. 


\section{Results}

The barriers to promoting recovery fell into three clusters based on a thematic analysis conducted by the authors: psychiatry knowledge, roles, and training; transforming public mental health systems; and environmental barriers to opportunity. Each set of barriers is discussed separately, with recommendations for addressing each barrier provided in Table 1 . The most prominent consensus points were the need to enhance community psychiatrists' knowledge of recovery, the need to redefine their roles in ways that support their efforts to promote recovery, and the need to invest in recovery-oriented training for psychiatrists throughout their careers.

\section{Barrier 1}

Many psychiatrists in the public mental health system lack sufficient knowledge and appreciation of recovery and have limited opportunities to learn more. Although participants in the program felt that most psychiatrists accepted recovery's values and beliefs - articulated by the comment "A great many of us went into the field of psychiatry precisely because we believe that people can get better and lead full lives" - the term recovery and the best ways for psychiatrists to act on those values and beliefs remained too vague in their minds. Participants felt that psychiatrists in administrative positions tended to be better informed and more enthusiastic about applying recovery principles, but those providing clinical supervision or working day to day with patients had little training and too few opportunities to learn about recovery and its implications for their work.

\section{Barrier 2}

Experienced psychiatrists are sometimes discouraged by the frequent perceived "failure" of their patients to move forward with their lives. Participants believed that they and their colleagues felt $\backslash$ a keen sense of responsibility for their patients' welfare, and although they were aware of the external barriers to success (including the failures of many public mental health systems and the impact of prejudice and discrimination), many were uncomfortable with encouraging patients to take substantial risks in pursuit of self-determined goals. Participants recognized that this aversion to risk sometimes conflicted with recovery's emphasis on hope and empowerment.

\section{Barrier 3}

Community psychiatrists have limited time to work with patients and few incentives to pursue recovery goals with them. Participants were especially concerned about their evolving roles and the lack of opportunity to work more effectively with individuals. These complaints were especially heartfelt: "Is it really asking too much for me to spend more than ten minutes a month with a patient?" Psychiatrists often feel that they have only a fleeting relationship with patients and are marginalized as persons who only prescribe medications (9) and as barriers to clients' pursuit of nonclinical goals.

\section{Barrier 4}

Psychiatrists have not exercised sufficient leadership in promoting recovery throughout the public mental health system. Participants felt that psychiatry's leaders have neither done enough to promote the importance of recovery within the field nor encouraged other fields within the public mental health arena to consider recovery as the basis for system transformation. They expressed concern that although there are prominent psychiatrists promoting recovery within the 
public mental health system, at the local level there is not enough outspoken advocacy in partnership with consumers and other practitioners - to emphasize recovery.

\section{Barrier 5}

There are too few community psychiatrists in the field today, and there is too little interest among future psychiatrists in working in public mental health. The participants were concerned that the field of community psychiatry appears to have little allure: practicing psychiatrists are leaving the field, and the numbers of psychiatric residents choosing community psychiatry are dwindling. The problems - low pay, the attenuated professional role of psychiatrists in community programs, and the severity of the problems experienced by clients of public mental health systems - have diminished the ranks of existing and emerging community psychiatrists (10). There was a sense that an emphasis on recovery might reignite interest in the field. Participants felt that public mental health systems continue to face substantial administrative, financial, and clinical problems that frustrate efforts to work within a more recovery-oriented framework.

\section{Barrier 6}

Current mental health reimbursement systems do not support recovery. Participants pointed out that federal, state, and local public mental health systems have not framed financial reimbursement systems to reflect recovery-oriented care. Despite the emphasis on recovery in public statements and formal planning documents, public mental health providers are still primarily focused on symptom remission and client stabilization, with limited opportunities to expand the number of reimbursable programs that emphasize community integration and recovery. Participants believed that both the existing framework of community support services and the emerging network of consumer-run programs are starved for funding.

\section{Barrier 7}

There are too few public mental health programs emphasizing recovery issues - such as empowerment, employment, and education - to which psychiatrists can refer patients. Participants were concerned that many core programs, including consumer-run services, employment-oriented programs, and housing opportunities, are not readily available. Without supports to address patient needs, including both spiritual connections and comprehensive health care, the public mental health system often fails to respond to the most basic recovery principles. Participants argued for a transformed mental health system that redirected funds to critical needs without limiting much-needed clinical services.

\section{Barrier 8}

Public mental health systems are uncoordinated, underfunded, and overly focused on symptom reduction, stabilization, and maintenance. Participants often commented on the lack of coordination among systems of services and supports, which made service planning and progress more difficult; the increasing demands for greater funding for acute care, which limited the availability of funding for community integration activities; and the continuing emphasis on symptoms as opposed to recovery.

\section{Barrier 9}


There is no systematic or standardized way in which most mental health systems can assess their effectiveness in achieving recovery-oriented goals at the individual or system levels. Despite efforts to clarify the definition of recovery and establish measurement standards, there is still considerable confusion about what mental health systems and psychiatrists should be achieving in a recovery-oriented system.

Much of the discussion about the need for improvements in the delivery of mental health services hinged on the broader issues of environmental barriers that limited opportunities for people to successfully participate in the community. Several commented on the public's continuing misperceptions about the presence of people with psychiatric disabilities in community settings and current political philosophy that government should play limited roles in people's lives.

\section{Barrier 10}

Community prejudices toward people with psychiatric disabilities remain a powerful factor in the lives of those with mental illnesses, blunting many opportunities through discriminatory public policies and exclusionary social practices. The participants felt that people with psychiatric disabilities often make only limited progress toward recovery-oriented goals within the context of a wary and sometimes hostile community in which such basic resources as housing, jobs, and social interactions are limited.

\section{Barrier 11}

Community support, expressed through the political process, still provides too-limited financial support and public policy advocacy to ensure that those with psychiatric disabilities in public mental health programs receive the services and can claim the rights they deserve. Participants were clear that the lack of community understanding about psychiatric disabilities translated into a series of public policy decisions that limited the funding for supports as well as the rights of people with psychiatric disabilities.

\section{Barrier 12}

Many people with psychiatric disabilities in public mental health systems are poor and are thus victimized by the same sets of social conditions - poor housing, low wages, and limited social participation, for example - as other people who live in poverty. Participants also saw people with psychiatric disabilities, particularly those who were poor and from minority, immigrant, or otherwise disenfranchised communities, as struggling against the same sets of social factors that limit the lives of their peers without disabilities.

\section{Discussion}

The goal of the symposium was to identify key barriers and recommend solutions for facilitating psychiatry's efforts in promoting recovery. The participants clearly indicated that psychiatrists must be far more active in aligning psychiatric policies, programs, and practices with recovery and community integration efforts. The recommendations that emerged from the oneday symposium lay out an ambitious agenda for community psychiatry. They suggest that there is much work to be done, not only within psychiatry but also within the sprawling public mental health system and, indeed, within the broader community. Although this was a first attempt to assess the views of psychiatrists about their ability to integrate recovery into their public policy 
and clinical roles, the barriers they have identified and the recommendations they have developed are reasonable and present a realistic challenge to the field. The formidable and complex nature of that challenge is underlined by the way this identification of barriers and recommendations raises more subtle issues: two particular concerns are raised here, but there are likely many others. First, it may be that underlying psychiatrists' concerns about their roles are the dramatic changes under way in the roles of psychiatrists. Changes in the relationships between psychiatrists and patients (for whom self-determination is a fundamental issue), between psychiatrists and other mental health professionals (who now want a broader role for themselves), and between psychiatrists and public or private insurers (with their demands for an emphasis on pharmacologic treatment) raise wide-ranging issues about the future roles and responsibilities of psychiatrists in facilitating recovery. Second, participants in this conference were more readily able to identify and support aspects of recovery that suggested the need for a greater focus and more substantial funding for a wide range of rehabilitation programs that respond to recovery-oriented goals than to identify and promote ways in which recovery principles could be integrated into their clinical practice. They were aware of few models, guidelines, or practice recommendations that could help individual psychiatrists move toward transforming the treatment environment - ways in which hope, empowerment, and opportunity would play out in the psychiatric milieu.

\section{Conclusions}

Our ambition is for this initial dialogue to help shape local, regional, and national discussion among psychiatrists and other mental health professionals within the mental health system, which would then lead to determined action in partnership with patients. This first look at psychiatric perspectives on these critical issues may serve as an impetus for enhancing psychiatry's role in promoting recovery.

\section{Acknowledgments and disclosures}

This study was partially supported by grant H133-B031109 to the University of Pennsylvania Collaborative on Community Integration from the National Institute on Disability and

Rehabilitation Research (Dr. Salzer, principal investigator). The authors thank Christine Simiriglia, Betsy Gorski, L.S.W., Ken Thompson, M.D., and Estelle Richman, M.A., for their support and involvement in this effort.

The authors report no competing interests.

\section{References}

1. Anthony WA: Recovery from mental illness: the guiding vision of the mental health services system in the 1990s. Psychiatric Rehabilitation Journal 16:11-23, 1993

2. Spaniol L, Gagne C, Koehler M: Recovery from serious mental illness: what is it and how to support people in their recovery, in The Psychological and Social Impact of Disability, 4th ed. Edited by Marinelli RP, Dell Orto AE. New York, Springer, 1999

3. Lieberman RP, Kopelowicz A: Recovery from schizophrenia: a concept in search of research. Psychiatric Services 56:735-742, 2005

4. Jacobson N, Greenley D: What is recovery? A conceptual model and explication. Psychiatric Services 52:482-485, 2001

5. Bellack AS: Scientific and consumer models of recovery in schizophrenia: concordance, contrasts, and implications. Schizophrenia Bulletin 32:432-442, 2006 
6. Achieving the Promise: Transforming Mental Health Care in America. Executive summary, pub no SMA-03-3832. Rockville, Md, Department of Health and Human Services, President's New Freedom Commission on Mental Health, 2003

7. Blanch AK, Fighs D, Tucker W, et al: Consumer- practitioners and psychiatrists share insights about recovery and coping. Disabilities Studies Quarterly 13:17-20, 1993

8. Davidson L, O'Connell M, Tondora J, et al: The top ten concerns about recovery encountered in mental health system transformation. Psychiatric Services 57:640-645, 2006

9. Gabbe GO: The psychiatrist as psychotherapist, in Psychiatry in the New Millennium. Edited by Weissman S, Sabshin M, Eist H. Washington, DC, American Psychiatric Press, 1998

10. Arce AA, Vergare MJ: Psychiatrists and interprofessional role conflicts in Community Mental Health Centers, in Community Mental Health Centers and Psychiatrists. Washington, DC, and Rockville, Md, Edited and published by the Joint Steering Committee of the American Psychiatric Association and the National Council of Community Mental Health Centers, 1985 